\title{
1 Morphogenesis of the islets of Langerhans is guided by extra-endocrine Slit2/3 signals
}

4 Jennifer M. Gilbert ${ }^{1}$, Melissa T. Adams ${ }^{1}$, Nadav Sharon ${ }^{2}$, Hariharan Jayaraaman ${ }^{1}$, Barak Blum ${ }^{1 *}$

$7 \quad{ }^{1}$ Department of Cell and Regenerative Biology, University of Wisconsin-Madison School of Medicine 8 and Public Health, 1111 Highland Avenue, Madison, WI 53705, USA.

$9{ }^{2}$ Department of Stem Cell and Regenerative Biology, Harvard University, 7 Divinity Avenue, Cambridge, 10 MA, 02138, USA.

11

$12 *$ Corresponding author: Barak Blum; bblum4@wisc.edu 


\section{Abstract}

14 The spatial architecture of the islets of Langerhans is vitally important for their correct function, and

15 alterations in islet morphogenesis often result in diabetes mellitus. We have previously reported that

16 Roundabout (Robo) receptors are required for proper islet morphogenesis. As part of the Slit-Robo

17 signaling pathway, Robo receptors work in conjunction with Slit ligands to mediate axon guidance, cell

18 migration, and cell positioning in development. However, the role of Slit ligands in islet morphogenesis

19 has not yet been determined. Here we report that Slit ligands are expressed in overlapping and distinct

20 patterns in both endocrine and non-endocrine tissues in late pancreas development. We show that

21 function of either Slit2 or Slit3, which are predominantly expressed in the pancreatic mesenchyme, is

22 required and sufficient for islet morphogenesis, while Slit1, which is predominantly expressed in the $\beta$

23 cells, is dispensable for islet morphogenesis. We further show that Slit functions as a repellent signal to

$24 \beta$ cells. These data suggest that clustering of endocrine cells during islet morphogenesis is guided, at

25 least in part, by repelling Slit2/3 signals from the pancreatic mesenchyme. 


\section{Introduction}

27 Blood glucose homeostasis is regulated in the pancreas by clusters of endocrine cells called the islets of Langerhans. Islets consist of five different endocrine cell types $(\alpha, \beta, \delta, P \mathrm{P}, \varepsilon)$, which secrete glucagon,

29 insulin, somatostatin, pancreatic polypeptide, and ghrelin, respectively. Murine islets exhibit a distinct cytoarchitecture consisting of a core of $\beta$-cells, surrounded by a mantle of $\alpha-, \delta$-, PP- and $\varepsilon$-cells. The $\beta$ cell core makes up roughly $80 \%$ of the islet mass, while the four other cell types make up the remaining 20\% (Kim et al., 2009; Steiner et al., 2010). This cytoarchitecture is thought to be important for proper islet function, and loss of this architectural makeup is described in obesity and diabetes in both mice and humans (Baetens et al., 1978; Cabrera et al., 2006; Kilimnik et al., 2011; Roscioni et al., 2016). While the architectural features of islets have been well-documented, the mechanisms controlling the formation this architecture are still largely unknown.

37 The Slit-Robo signaling pathway has roles in a number of developmental processes, primarily axon guidance, cell movement, and cell adhesion (Blockus and Chédotal, 2016; Chédotal, 2007; Wu et al., 2017; Ypsilanti and Chedotal, 2014; Ypsilanti et al., 2010). Slit ligand binding to Robo receptors can induce cell migration using repulsive or attractive cues in a context-dependent manner. In the

41 developing mouse, Slit-Robo signaling provides a repulsive corridor to prevent migrating axons from straying from their path during innervation (Brose et al., 1999; Dickson and Gilestro, 2006). Slit-Robo

43 binding inactivates Rho GTPases, inhibiting actin polymerization and driving the cell away from the

44 direction of the Slit signal (Wu et al., 2017; Ypsilanti et al., 2010). Conversely, Slit uses attractive cues to promote vascular development and angiogenesis. In this context, Slit-Robo interactions activate Rho

46 GTPases, inducing actin polymerization in the direction of the Slit signal (Rama et al., 2015; Wu et al., 47 2017; Ypsilanti et al., 2010; Zhang et al., 2009). While Slit and Robo are a canonical signaling pair, both 
components have alternative binding partners; Slit ligands are able to bind semaphorins, ephrins, plexin, and neuronatin to regulate cell migration and metabolic function in specific tissues (Brose et al., 1999; Delloye-Bourgeois et al., 2015; Svensson et al., 2016; Wright et al., 2012). Robo receptors are

51 able to bind the fibronectin leucine rich transmembrane protein 3 (FLIRT3), and are capable of forming

52 homodimers to induce axonal growth (Hivert, 2002; Leyva-Díaz et al., 2014; Tong et al., 2019).

53 We have recently described a role for Robo receptors in pancreatic islet architecture (Adams et al.,

54 2018). Specifically, we showed that genetic deletion of Robo1 and Robo2 in $\beta$-cells (Robo $\beta K O$ ) results

55 in loss of stereotypic murine islet architecture, without affecting $\beta$-cell differentiation or maturation.

56 These Robo-depleted islets have a marked invasion of $\alpha$ - and $\delta$-cells into the $\beta$-cell core. Given the

57 conserved role of Slits as the canonical Robo ligands and our recent findings that Robo receptors

58 regulate endocrine cell type sorting in the islet, we set to investigate the role of Slit ligands in islet

59 morphogenesis.

60

61 Results

62 Slits ligands are expressed in different compartments in the developing mouse pancreas.

63 To test the hypothesis that Slits are involved in Robo-mediated control of islet architecture during

64 development, we first examined whether any of the Slit ligands are expressed in the pancreas at the

65 time of islet morphogenesis. We queried a gene expression database, generated by Krentz and

66 colleagues (Krentz et al., 2018), which contains single-cell RNA-Seq data from embryonic mouse

67 pancreata. We found that Slit1 expression is present in a subset of endocrine progenitor cells at

68 embryonic day (E)15.5, and becomes enriched in $\beta$-cells by E18.5. Slit2 and Slit3 expression is 
distributed between pancreatic mesenchyme, acinar, and ductal cell types with negligible expression in

the endocrine compartment at both time points (Figure 1).

71 To confirm the expression of Slits in the pancreas in vivo, we analyzed pancreata from Slit $1^{\text {GFP }}$, Slit2 ${ }^{\text {GFP }}$,

72 and Slit3 ${ }^{\text {LacZ }}$ mice, which have knock-in reporters at their respective endogenous Slit loci (Plump et al.,

73 2002; Yuan et al., 2003). We identified strong GFP expression in Slit1 ${ }^{\text {GFP/+ }}$ mice both in E18.5 and adult

74 islets. This staining pattern overlapped with insulin, indicating that Slit1 is expressed in $\beta$-cells at both

75 stages (Figure 2A). We did not detect Slit2 ${ }^{\text {GFP }}$ (Figure 2A) or Slit3 ${ }^{\text {LacZ }}$ (Figure $2 \mathrm{~B}$ ) in either the embryonic

76 or the adult islets. However, Slit3 ${ }^{\text {LacZ }}$ expression was detected in pancreatic tissues outside of the islet

77 (Figure 2B). Slit2 ${ }^{\text {GFP }}$ expression was seen in other tissues, indicating that the lack of Slit2 ${ }^{\text {GFP }}$ signal in the

78 developing pancreas is not caused by a problem with the reporter (Supplementary Figure 1). A

79 previous report by Escot and colleagues identified Slit3 expression in the developing pancreatic

80 mesenchyme (Escot et al., 2018). While we were not able to detect Slit2 ${ }^{G F P}$ expression, data from

81 single-cell RNA Sequencing (scRNAseq) indicates that it is also expressed in pancreatic mesenchyme

82 during development (Krentz et al., 2018). We concluded that Slit1 is the predominant Slit expressed

83 inside the islets, and that Slit3 and perhaps Slit2 are expressed outside of the islet during pancreatic

84 development.

85

Loss of a single Slit ligand does not compromise islet architecture.

87 Slit and Robo are conserved binding partners, and loss of Robo in the islets of Robo $\beta K O$ mice results in severely altered islet architecture (Adams et al., 2018). We hypothesized that if Slits mediate Roboregulated islet architecture, then eliminating Slit expression would phenocopy the islet organization defects in Robo $\beta K O$ islets. Whole-body Slit1-null (Slit1 $\left.{ }^{\text {GFP/GFP }}\right)$ and Slit3-null (Slit3 ${ }^{\text {LacZ/LacZ }}$ ) mice are viable 
91 to adulthood. We performed positional cell counting on the islets of these mice as previously described

92 (Adams et al., 2018) to determine whether these mutants exhibited islet organizational defects. In

93 contrast to the phenotype seen in Robo $\beta K O$ islets, individual Slit1 or Slit3 mutant islets display

94 completely normal architecture (Figure $\left.3 A_{-}-C\right) . \alpha_{-}, \beta-$, and $\delta$-cells remain restricted to their respective

95 niches; the $\beta$-cells reside in the core, while the $\alpha$ - and $\delta$-cells remain in the islet mantle. We also found

96 no significant difference between control islets and Slit1 or Slit3 mutant islets in islet size (Figure 3D) or

97 circularity (Figure 3E). Whole-body Slit2-null (Slit2 ${ }^{G F P / G F P}$ ) animals die shortly after birth. We thus

98 examined pancreata of E18.5 Slit2 ${ }^{\text {GFP/GFP }}$ embryos. Evidence of altered islet architecture in Robo $\beta K O$

99 mutants can be seen at E18.5; however, we did not observe overt defects in the architecture of

100 Slit2 $2^{\text {GFP/GFP }}$ islets at this time point (Figure 3F). Taken together, these results indicate that individual Slits

101 are either not required for, or compensate for each other in, Robo-mediated control of islet

102 architecture.

103

104 Slit2 and Slit3 compensate for each other and are required for islet morphogenesis.

105 Slit ligands are highly similar in amino acid sequence, particularly in their Robo-binding domains (Figure

$1064 \mathrm{~A})$. Thus, it is possible that the different Slit ligands compensate for each other during islet

107 morphogenesis. We tested the extent to which multiple Slit ligands are required for islet architecture

108 by analyzing islet formation in combinatorial Slit mutants. Slit $1^{\text {GFP/GFP }}$;Slit3 ${ }^{\text {Lacz/LacZ }}$ double knockouts live

109 to adulthood and appear normal, with no detectable alterations in islet architecture, size, or circularity

110 (Figure 4B-F). To circumvent the neonatal lethality of Slit2 ${ }^{\text {GFP/GFP }}$ mice, we analyzed the pancreata of

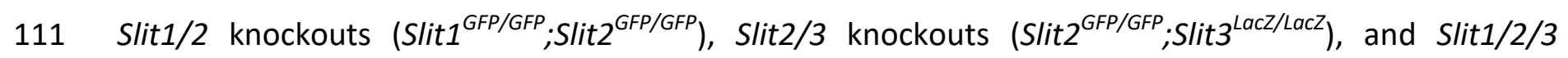

112 knockouts (Slit1 ${ }^{\text {GFP/GFP }} ;$ Slit2 $2^{\text {GFP/GFP }} ;$ Slit3 ${ }^{\text {LacZ/LacZ })}$ at E18.5 or PO. Slit1/2 knockout islets show no indications 
113 of altered architecture, but Slit2/3 and Slit1/2/3 knockouts have disorganized islets (Figure $4 \mathrm{G}$ ). To

114 quantify this phenotype, we scored islets as either intact (insulin-positive cells surrounded by glucagon-

115 positive cells), intermediate (clusters of insulin-positive cells disrupted by glucagon-positive or non-

116 endocrine cells), or disrupted (single cells or clusters of endocrine cells that are not forming islet

117 structures) (Figure 4H). Double-blinded scoring of islets from the above genotypes revealed that wild

118 type and Slit1/2 knockouts have few disrupted islets and similar percentages of intact and intermediate

119 islets (WT intact: 49\%, intermediate: 40\%, disrupted: 11\%. Slit1/2 KO intact: 43\%, intermediate: 46\%,

120 disrupted: $11 \%$ ). On the other hand, Slit2/3 and Slit1/2/3 knockouts had very few intact islets and

121 increased numbers of intermediate and disrupted islets (Slit2/3 KO intact: 8\%, intermediate: 53\%,

122 disrupted: 39\%. Slit1/2/3 KO intact: 8\%, intermediate: 60\%, disrupted: $32 \%)$. Taken together, the data

123 suggest that Slit1 (expressed in the islet itself) is dispensable, while Slit2 and Slit3 (expressed outside of

124 the islet) compensate for each other and are required for proper islet formation.

\section{Slits act as repellent factors to influence $\beta$ cell migration}

127 Because Slit2/3 and Slit1/2/3 mutant islets are disrupted and do not cluster tightly, we wondered

128 whether this indicates failure of $\beta$-cells to migrate properly during islet morphogenesis. To test this

129 hypothesis, we performed Transwell cell migration assays using INS-1 cells. INS-1 cells seeded in the

130 top chamber of a cell culture insert above INS-1 conditioned media showed strong migratory activity,

131 while INS-1 cells seeded above fresh, untreated INS-1 culture media did not (Figure 5A-C). INS-1 cells

132 seeded above conditioned media supplemented with $2.5 \mu \mathrm{g}$ recombinant SLIT1, SLIT2, and SLIT3

133 displayed a significantly reduced ability to migrate (Figure 5B,C), suggesting that Slits influence $\beta$-cell

134 migration through cell-cell repulsion mechanisms during islet morphogenesis. 


\section{Discussion}

137 In this study, we demonstrate that Slit ligands are required for pancreatic islet architecture.

138 Simultaneous loss of all three Slits results in a disrupted, "islet explosion-like" phenotype, which is also

139 observed in Slit2 ${ }^{\text {GFP/GFP }}$;Slit3 ${ }^{\text {LacZ/LacZ }}$ knockouts. These findings lead us to conclude that Slit1 is

140 dispensable for, and that Slit2 and Slit3 are required for and have redundant roles in, islet

141 morphogenesis.

142 The exact mechanism of Slits in islet morphogenesis is unknown; however, the expression pattern of

143 Robo in the pancreas provides some clues. Slit and Robo are ligand-receptor binding partners in the

144 Slit-Robo signaling pathway. During mammalian development, Slit and Robo occupy adjacent tissues,

145 specifying complimentary expression patterns in the developing organism (Yuan et al., 1999). While all

146 three Slits have expression patterns unique to their specific domain, they also have overlapping regions

147 of expression, suggesting some genetic redundancy. Interestingly, Slit2 and Slit3 share more expression

148 domains with each other than either of them do with Slit1 (Yuan et al., 1999). We have observed a

149 similar framework in the mouse pancreas: Robo is primarily expressed in endocrine cells (Adams et al.,

150 2018), while Slit2 and Slit3 have overlapping expression patterns in pancreatic mesenchyme. These

151 complimentary and overlapping regions of expression are hallmarks of ligand-receptor binding

152 partners, and suggest that mesenchymal Slit2 and Slit3 interact with endocrine Robo to coordinate islet

153 morphogenesis. We propose that Slit2/3 signals from the mesenchyme are picked up by Robo

154 receptors on the surface of developing islet endocrine cells. These endocrine cells are then repelled

155 away from the direction of the Slit signal, allowing for islet clustering to occur. Loss of this signal results

156 in a failure of islet morphogenesis, thus the "islet explosion" phenotype described above. It is likely 
157 that Slits are not the only signal required for morphogenesis, as some of the islets in

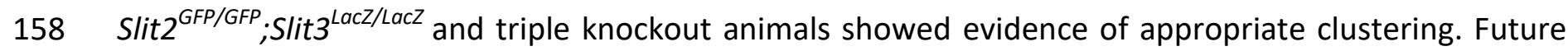
159 work will determine whether other ligands or even Robo-Robo interactions are involved in islet 160 morphogenesis.

161 It is commonly held that islet morphogenesis is outlined by delamination of endocrine progenitors 162 from the pancreatic duct, followed by their migration as individual cells though the mesenchyme and 163 aggregation into islets (Pan and Wright, 2011), implying that $\beta$-cells respond to attractive cues from the 164 islets. Indeed, we have observed strong Transwell migration of $\beta$-cells towards their own conditioned 165 medium, demonstrating that $\beta$-cells are attracted towards $\beta$-cells. However, we further provide 166 evidence to suggest mesenchymal Slits repel $\beta$-cells during islet morphogenesis. These results are in 167 support of the recent observation that endocrine progenitors remain physically connected throughout 168 islet morphogenesis (Sharon et al., 2019), and suggest that after $\beta$-cell delamination, repulsion of the $169 \beta$-cells by mesenchymal Slits pushes them into the center of the islet, thus maintaining the core-mantle 170 architecture. Taken together, we propose that both attractive and repulsive signals operate together in 171 forming the canonical murine islet architecture.

172 The role of Slit1 in islet morphogenesis remains elusive. The islet architecture phenotypes seen in 173 Slit2 ${ }^{\text {GFP/GFP }}$;Slit3 ${ }^{\text {LacZ/LacZ }}$ animals are not significantly different in triple knockouts, suggesting that Slit1 174 does not have any influence on islet architecture. In addition, Slit1 expression does not overlap with 175 Slit2 or Slit3, thus it is unlikely to be redundant. Morover, Slit1 is strongly expressed in a subset of $\beta$ 176 cells both during development and in the adult. Slits have been previously demonstrated to provide a 177 protective effect on $\beta$-cells, as well as potentiate insulin secretion (Yang et al., 2013). It is thus plausible that Slit1 is tasked with the protective and secretory roles in the islet, while the transient expression of 
bioRxiv preprint doi: https://doi.org/10.1101/2020.06.15.153353; this version posted August 25, 2020. The copyright holder for this preprint (which was not certified by peer review) is the author/funder, who has granted bioRxiv a license to display the preprint in perpetuity. It is made available under aCC-BY-NC-ND 4.0 International license.

179 Slit2 and Slit3 in the mesenchyme during development is responsible for islet morphogenesis. How the 180 expression of Slit1 in $\beta$-cells does not interfere with the function of Slit2 and Slit3 from the 181 mesenchyme during islet morphogenesis is intriguing, and remains to be elucidated. 


\section{Methods}

183 Animals

184 All animal experiments were conducted in accordance with the University of Wisconsin-Madison IACUC 185 guidelines under approved protocol \#M005221. Robo1; Robo2 flx (Branchfield et al., 2016), Ins2-Cre 186 (Postic et al., 1999), H2B-mCherry (Blum et al., 2014), Slit1 ${ }^{\text {GFP }}$, Slit2 ${ }^{\text {GFP }}$ (Plump et al., 2002), Slit3 ${ }^{\text {LacZ }}$ 187 (Yuan et al., 2003) alleles have been previously described.

Expression Analysis

190 tSNE plots of sc-RNA Seq obtained from the Lynn Lab's Single Cell Gene Expression Atlas 191 (https://lynnlab.shinyapps.io/embryonic pancreas/) (Krentz et al., 2018).

193 Immunostaining

194 Pancreata were dissected from adult ( 8week old), embryonic (E18.5), or newborn (P0) mice, fixed in $1954 \%$ paraformaldehyde for 1 hour at room temperature (20-30 minutes for E18.5 and P0), preserved in $19630 \%$ sucrose, embedded in OCT (Leica), then sectioned onto slides. Slides were stained according to 197 the following protocol: 1 hour block in 10\% Normal Donkey Serum in PBST, 1 hour primary antibody 198 incubation, 3x10 min PBST washes, 1 hour secondary antibody incubation in dark, 3x10 min PBST 199 washes, mount slides in Fluoromount-G (Thermo Fisher). The following primary antibodies were used: 200 Guinea Pig anti-Insulin 1:800 (Dako), Guinea Pig anti-Insulin pre-diluted 1:6 (Dako 1R002), Chicken anti201 GFP 1:1000 (Abcam ab13970), Rabbit anti-Glucagon 1:200 (Cell Signaling 2760), Goat anti-Somatostatin 202 1:50 (Santa Cruz), Rabbit anti-Somatostatin 1:800 (Phoenix G-060-03), DAPI 1:10,000 (Sigma 9542). The 
203 following secondary antibodies were used at 1:500: Alexa 647 anti-Guinea Pig, Alexa 594 anti-Rabbit,

204 Alexa 594 anti-Goat, Alexa 488 anti-Rabbit, Alexa 488 anti-Chicken.

205 For eye analysis, tissues were dissected and fixed in $4 \%$ paraformaldehyde for 2 hours at $4^{\circ} \mathrm{C}$. Tissues

206 were preserved in a series of sucrose solutions (10\%, 20\% sucrose) for 1.5 hours each. Tissues were

207 further preserved in 30\% sucrose overnight, embedded in OCT, then sectioned and stained as above.

208 For $\beta$-galactosidase staining, tissues were fixed in $4 \%$ paraformaldehyde for 1 hour at room 209 temperature (or 20-30 minutes for E18.5 tissue). Fixed tissues were stained with X-gal solution (Roche 21011828673001 ) for 22 hours at $37^{\circ} \mathrm{C}$, then preserved, embedded, and sectioned as above. Insulin 211 staining on these tissues was done using the Vectastain ABC HRP kit (Vector Labs PK-4007), NovaRED 212 kit (Vector Labs SK-4800), and mounted with VectaMount (Vector Labs H-5000). Slides for expression 213 analysis imaged using a Zeiss Axio Observer Z1.

215 Cell Counting, Shape, Size Analysis

216 Slides used for cell counting or shape and size analysis were imaged on a Nikon A1RS confocal 217 microscope. Confocal z-stacks were converted to maximum intensity projected images. The number of $218 \alpha$ - and $\delta$ - cells were counted using the ImageJ Cell Counter tool. $\alpha$ - or $\delta$ - cells were considered in the 219 islet periphery if they were within the first two cell layers of the islet. For shape and size analysis, islets 220 were outlined and a threshold was applied in ImageJ. The Analyze Particles tool then gave readout of 221 islet size in $\mu \mathrm{m}^{2}$ and a circularity score (between $0-1$, where 1 indicates a perfect circle). A minimum of 22210 islets were analyzed across at least three different tissue sections per mouse. Analysis performed on $223 n=3$ mice for each genotype. $\alpha$ - and $\delta$-cell percentages, islet size, and islet circularity values were 224 averaged for each mouse and plotted in Prism. 
226 Amino Acid Alignment

227 Amino acid sequence and domain information were obtained from Yuan et al., 1999. Pairwise 228 alignment scores of amino acid sequences were provided by ClustalW (https://www.genome.jp/tools229 bin/clustalw).

231 Islet Scoring

232 Islet scoring was performed on images of tissue sections stained for insulin, glucagon, and DAPI. Z-stack 233 images were converted to maximum intensity projected images, and randomly assigned a number 234 identifier. Four independent trials (by four different researchers) of double-blinded scoring was 235 performed on 197 images, comprising at least 10 images spanning four different tissue sections per 236 mouse, and at least 3 mice per genotype.

239 INS-1 cells (AddexBio) were maintained in culture media containing RPMI-1640 (ThermoFisher), 10\% $240 \mathrm{FBS}, 1 \%$ penicillin/streptomycin, and supplemented with $0.05 \mathrm{mM} \beta$-mercaptoethanol. Cells were 241 seeded at a density of 250,000 cells $/ \mathrm{mL}$ in Transwell cell culture inserts with $8 \mu \mathrm{M}$ pores (Sigma). 242 Inserts were placed into wells containing either $700 \mu \mathrm{L}$ culture media, $700 \mu \mathrm{L}$ INS-1 conditioned media, 243 or $700 \mu \mathrm{L}$ INS-1 conditioned media supplemented with $2.5 \mu \mathrm{g}$ each recombinant SLIT1, SLIT2, and SLIT3 244 (R\&D Systems) and cultured at $37^{\circ} \mathrm{C}$ for 48 hours. Inserts were then fixed in $4 \%$ paraformaldehyde for 24520 minutes, unmigrated cells were wiped off the top of the insert, and then inserts were incubated in $2460.08 \%$ crystal violet and a 1:1,000 concentration of DAPI to visualize the cells. Nine non-overlapping 
247 field of view images were taken for each insert. Three images per insert were chosen at random for

248 quantification. Results are reported as the average number of cells that migrated per field of view.

250 Statistical Analysis

251 All data reported as mean \pm SEM unless otherwise indicated. P-values calculated using Student's T-test

252 in Prism GraphPad 7 unless otherwise indicated. Any p-value $<0.05$ was considered significant and 253 marked with an asterisk.

\section{Author Contributions}

256 Conceptualization, B.B. and J.M.G; Methodology, B.B. and J.M.G; Investigation, J.M.G, M.T.A., N.S, and 257 H.J.; Formal Analysis, J.M.G, M.T.A., N.S, and H.J.; Writing Original Draft, B.B and J.M.G.; Writing, 258 Review and Editing, all authors; Funding Acquisition, B.B.; Supervision, B.B.

\section{Acknowledgements}

261 We thank members of the Blum lab, especially Bayley Waters and Dex Nimkulrat for valuable 262 discussion and comments on the manuscript. We thank Le Ma, David Ornitz, Alain Chedotal, and Marc 263 Tessier-Lavigne for mice. We are grateful to Francis Lynn and Nicole Krentz for allowing us to use their 264 scRNA-seq data, and to Cody Frederickson for help generating figures. We are also grateful to Lance 265 Rodenkirch and the UW-Madison Optical Imaging Core for help with imaging. This work was funded in 266 part by the following grants. R01DK121706 from the NIDDK, the DRC at Washington University Pilot 267 Grant P30DK020579, and Pilot Award UL1TR000427 from the UW-Madison Institute for Clinical and 268 Translational Research (ICTR). JMG and MTA were funded by 5T32GM007133-44, a graduate training 
bioRxiv preprint doi: https://doi.org/10.1101/2020.06.15.153353; this version posted August 25, 2020. The copyright holder for this preprint (which was not certified by peer review) is the author/funder, who has granted bioRxiv a license to display the preprint in perpetuity. It is made available under aCC-BY-NC-ND 4.0 International license.

269 award from the UW-Madison Stem Cell \& Regenerative Medicine Center, and an Advanced 270 Opportunity Fellowship through SciMed Graduate Research Scholars at UW-Madison. 


\section{References}

Adams, M. T., Gilbert, J. M., Hinojosa Paiz, J., Bowman, F. M. and Blum, B. (2018). Endocrine cell type sorting and mature architecture in the islets of Langerhans require expression of Roundabout receptors in $\beta$ cells. Sci. Rep. 8, 10876.

Baetens, D., Stefan, Y., Ravazzola, M., Malaisse-Lagae, F., Coleman, D. L. and Orci, L. (1978). Alteration of islet cell populations in spontaneously diabetic mice. Diabetes 27, 1-7.

Blockus, H. and Chédotal, A. (2016). Slit-Robo signaling. Development 143, 3037-3044.

Blum, B., Roose, A. N., Barrandon, O., Maehr, R., Arvanites, A. C., Davidow, L. S., Davis, J. C., Peterson, Q. P., Rubin, L. L. and Melton, D. A. (2014). Reversal of $\beta$ cell de-differentiation by a small molecule inhibitor of the TGF $\beta$ pathway. Elife 3, e02809.

Branchfield, K., Nantie, L., Verheyden, J. M., Sui, P., Wienhold, M. D. and Sun, X. (2016). Pulmonary neuroendocrine cells function as airway sensors to control lung immune response. Science 351, 707-710.

Brose, K., Bland, K. S., Wang, K. H., Arnott, D., Henzel, W., Goodman, C. S., Tessier-lavigne, M., Kidd, T., Way, D. N. A. and Francisco, S. S. (1999). Slit Proteins Bind Robo Receptors and Have an Evolutionarily Conserved Role in Repulsive Axon Guidance. Cell 96, 795-806.

Cabrera, O., Berman, D. M., Kenyon, N. S., Ricordi, C., Berggren, P.-O. and Caicedo, A. (2006). The unique cytoarchitecture of human pancreatic islets has implications for islet cell function. Proc. Natl. Acad. Sci. U. S. A. 103, 2334-9.

Chédotal, A. (2007). Slits and their receptors. Adv. Exp. Med. Biol. 621, 65-80.

Delloye-Bourgeois, C., Jacquier, A., Charoy, C., Reynaud, F., Nawabi, H., Thoinet, K., Kindbeiter, K., Yoshida, Y., Zagar, Y., Kong, Y., et al. (2015). PlexinA1 is a new Slit receptor and mediates axon 
guidance function of Slit C-terminal fragments. Nat. Neurosci. 18, 36-45.

Dickson, B. J. and Gilestro, G. F. (2006). Regulation of Commissural Axon Pathfinding by Slit and its Robo Receptors. Annu. Rev. Cell Dev. Biol. 22, 651-675.

Escot, S., Willnow, D., Naumann, H., Di Francescantonio, S. and Spagnoli, F. M. (2018). Robo signalling controls pancreatic progenitor identity by regulating Tead transcription factors. Nat. Commun. 9, 5082.

Hivert, B. (2002). Robo1 and Robo2 Are Homophilic Binding Molecules That Promote Axonal Growth.

302 Mol. Cell. Neurosci. 21, 534-545.

Kilimnik, G., Zhao, B., Jo, J., Periwal, V., Witkowski, P. and Misawa, R. (2011). Altered Islet Composition and Disproportionate Loss of Large Islets in Patients with Type 2 Diabetes. PLoS One 6, e27445.

Kim, A., Miller, K., Jo, J., Kilimnik, G., Wojcik, P. and Hara, M. (2009). Islet architecture: A comparative study. Islets 1, 129-136.

Krentz, N. A., Lee, M., Xu, E. E., Sasaki, S. and Lynn, F. C. (2018). Single cell transcriptome profiling of mouse and hESC-derived pancreatic progenitors. Stem Cell Reports 11, 1551-1564.

Pan, F. C. and Wright, C. (2011). Pancreas organogenesis: From bud to plexus to gland. Dev. Dyn. 240, $530-565$.

Plump, A. S., Erskine, L., Sabatier, C., Brose, K., Epstein, C. J., Goodman, C. S., Mason, C. A. and Tessier-Lavigne, M. (2002). Slit1 and Slit2 cooperate to prevent premature midline crossing of retinal axons in the mouse visual system. Neuron 33, 219-232.

Postic, C., Shiota, M., Niswender, K. D., Jetton, T. L., Chen, Y., Moates, J. M., Shelton, K. D., Lindner, J., Cherrington, A. D. and Magnuson, M. A. (1999). Dual roles for glucokinase in glucose 
homeostasis as determined by liver and pancreatic $\beta$ cell-specific gene knock-outs using Cre recombinase. J. Biol. Chem. 274, 305-315.

Rama, N., Dubrac, A., Mathivet, T., Ní Chárthaigh, R.-A., Genet, G., Cristofaro, B., Pibouin-Fragner, L.,

Roscioni, S. S., Migliorini, A., Gegg, M. and Lickert, H. (2016). Impact of islet architecture on $\beta$-cell heterogeneity, plasticity and function. Nat. Rev. Endocrinol. 12, 695-709.

Schonhoff, S. E., Giel-Moloney, M. and Leiter, A. B. (2004). Neurogenin 3-expressing progenitor cells in the gastrointestinal tract differentiate into both endocrine and non-endocrine cell types. Dev. Biol.

\section{Sharon, N., Chawla, R., Mueller, J., Gifford, D. K., Trapnell, C., Melton, D., Sharon, N., Chawla, R.,} Mueller, J., Vanderhooft, J., et al. (2019). A Peninsular Structure Coordinates Asynchronous Differentiation with Morphogenesis to Generate Pancreatic Islets. Cell. 176, 790-804.

Steiner, D. J., Kim, A., Miller, K. and Hara, M. (2010). Pancreatic islet plasticity: Interspecies comparison of islet architecture and composition. Islets 2, 135-145.

Svensson, K. J., Long, J. Z., Jedrychowski, M. P., Cohen, P., Lo, J. C., Serag, S., Kir, S., Shinoda, K., Tartaglia, J. A., Rao, R. R., et al. (2016). A secreted slit2 fragment regulates adipose tissue thermogenesis and metabolic function. Cell Metab. 23, 454-466.

Tong, M., Jun, T., Nie, Y., Hao, J. and Fan, D. (2019). The role of the SLIT/Robo signaling pathway. J. Cancer 10, 2694-2705.

Wright, K. M., Lyon, K. A., Leung, H., Leahy, D. J., Ma, L. and Ginty, D. D. (2012). Dystroglycan Organizes Axon Guidance Cue Localization and Axonal Pathfinding. Neuron 76, 931-944. 
338 Wu, M. F., Liao, C. Y., Wang, L. Y. and Chang, J. T. (2017). The role of Slit-Robo signaling in the regulation of tissue barriers. Tissue Barriers 5, 1-17.

340

Yang, Y. H. C., Manning Fox, J. E., Zhang, K. L., MacDonald, P. E. and Johnson, J. D. (2013). Intraislet SLIT-ROBO signaling is required for beta-cell survival and potentiates insulin secretion. Proc. Natl. Acad. Sci. U. S. A. 110, 16480-5.

Ypsilanti, A. R. and Chedotal, A. (2014). Roundabout receptors. Adv. Neurobiol. 8, 133-64.

Ypsilanti, A. R., Zagar, Y. and Chedotal, A. (2010). Moving away from the midline: new developments for Slit and Robo. Development 137, 1939-1952.

Yuan, W., Zhou, L., Chen, J. H., Wu, J. Y., Rao, Y. and Ornitz, D. M. (1999). The mouse SLIT family: secreted ligands for ROBO expressed in patterns that suggest a role in morphogenesis and axon guidance. Dev. Biol. 212, 290-306.

Yuan, W., Rao, Y., Babiuk, R. P., Greer, J. J., Wu, J. Y. and Ornitz, D. M. (2003). A genetic model for a central (septum transversum) congenital diaphragmatic hernia in mice lacking Slit3. Proc Natl Acad Sci USA 100, 5217-5222.

Zhang, B., Dietrich, U. M., Geng, J. G., Bicknell, R., Esko, J. D. and Wang, L. (2009). Repulsive axon guidance molecule Slit3 is a novel angiogenic factor. Blood 114, 4300-4309. 


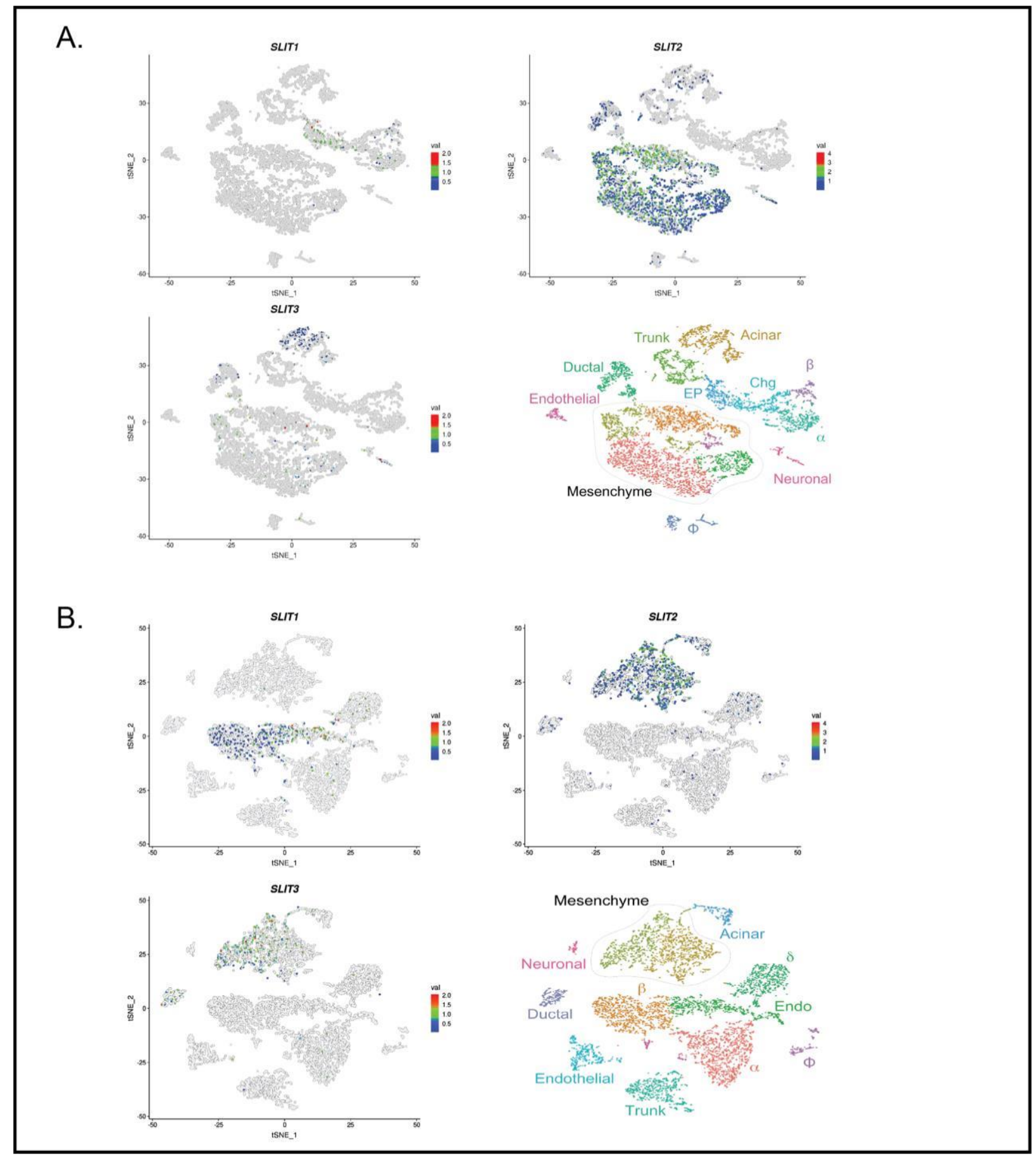

Figure 1: Slit transcripts are expressed in different compartments in the developing murine pancreas. Single-cell RNA-Seq data (scRNA-Seq) adapted from Krentz and colleagues (Krentz et al. 2018). tSNE plots depicting Slit1, Slit2, and Slit3 expression in pancreatic cells. Time points analyzed are E15.5 (A) and E18.5 (B). Slit1 is restricted to the endocrine compartment, while Slit2 and Slit3 localize with the mesenchyme/acinar compartment. 
A.
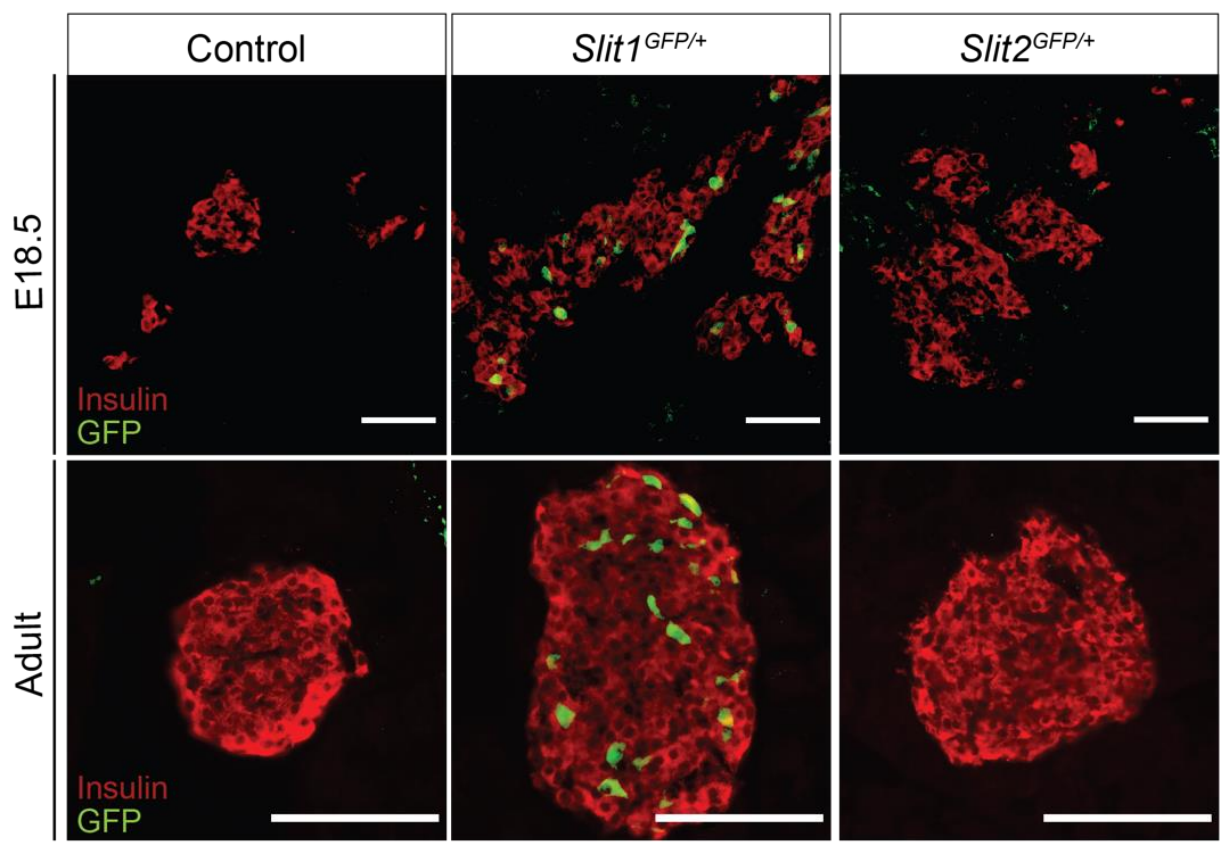

B.

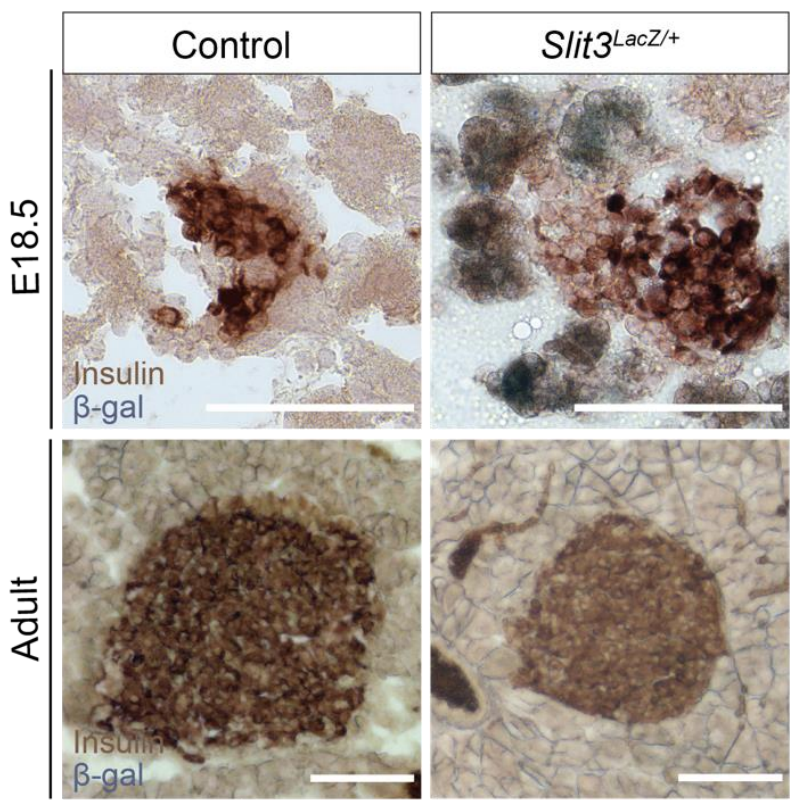

Figure 2: Slit1, but not Slit2 or Slit3, is expressed in the mouse islet from embryonic stages to adulthood. (A) Immunofluorescence staining of $\beta$-cells (Insulin, red) and Slit1, Slit2 (GFP, green) in E18.5 and adult heterozygous knock-in mice. (B) B-gal staining of Slit3 (LacZ, blue) in E18.5 and adult heterozygous knock-in mice. $\beta$-gal staining (Slit3 expression) is apparent in nonendocrine tissue surrounding the islet in the embryo. Scale bar $=100$ microns. 


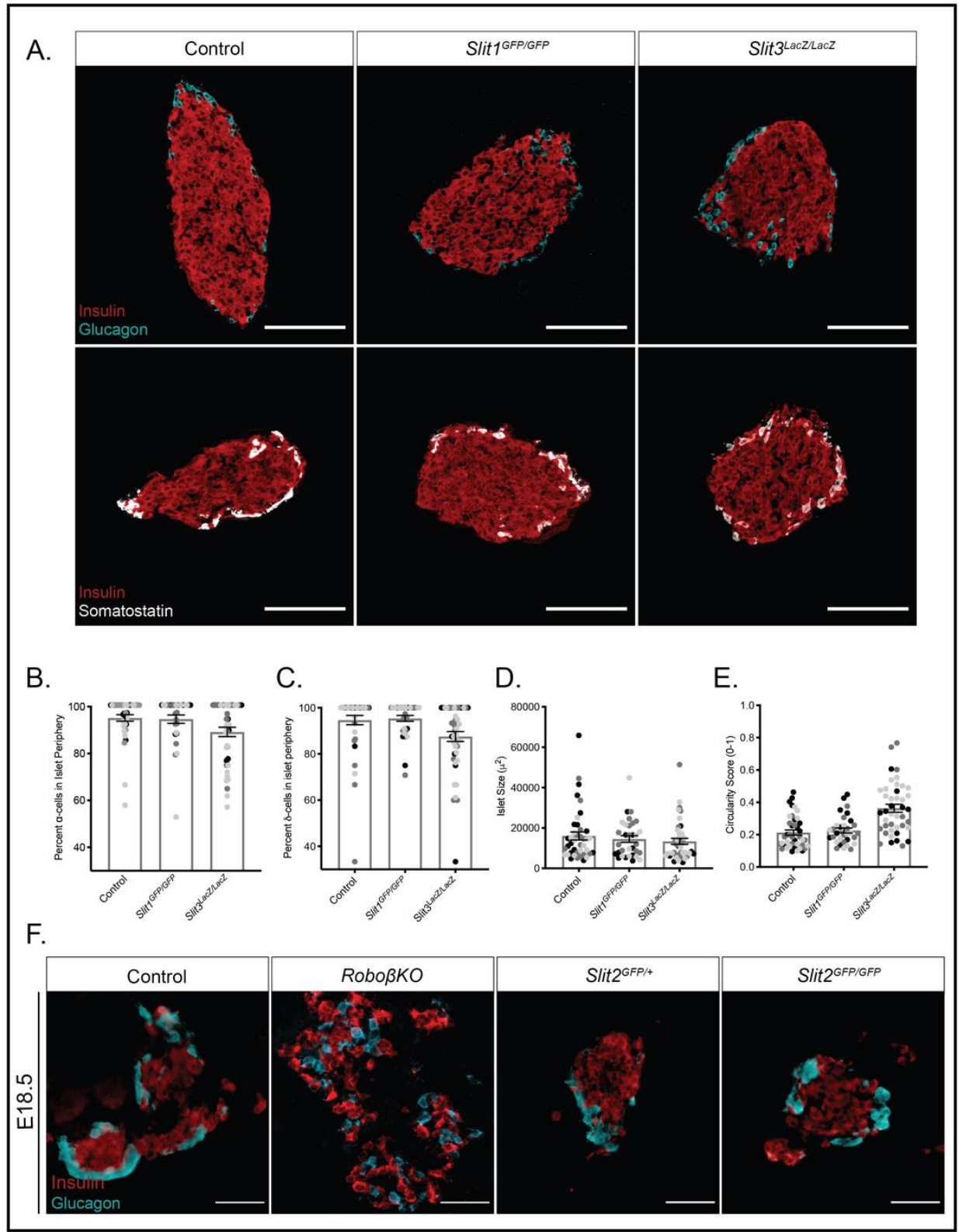

Figure 3: Loss of a single Slit ligand does not compromise islet architecture. (A) Immunofluorescence staining of $\beta$-cells (Insulin, red), $\alpha$-cells (Glucagon, cyan) and $\delta$-cells (Somatostatin, white) in adult ( 8 week old) homozygous knockout mice. Scale bar $=100$ microns. (B) Percentage of $\alpha$-cells found in the islet periphery out of total $\alpha$-cells. (C) Percentage of $\delta$-cells found in the islet periphery out of total $\delta$-cells. (D) Average islet size (E) Average islet circularity (as noted by a circularity score of $0-1$, where 1 is a perfect circle). (F) Immunofluorescence staining of $\beta$-cells (Insulin, red) and $\alpha$-cells (Glucagon, cyan) in E18.5 control, Ins2-Cre;Robo1 ${ }^{-/} ; R_{0 b o 2^{f l} / f f x}$, and Slit2 mice. Scale bar $=50$ microns. Data presented as mean $\pm S E M$. 


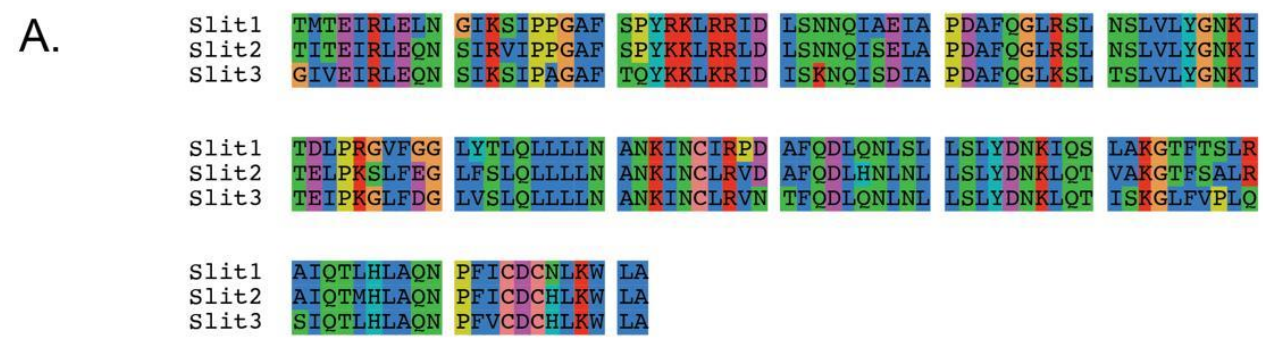

B.
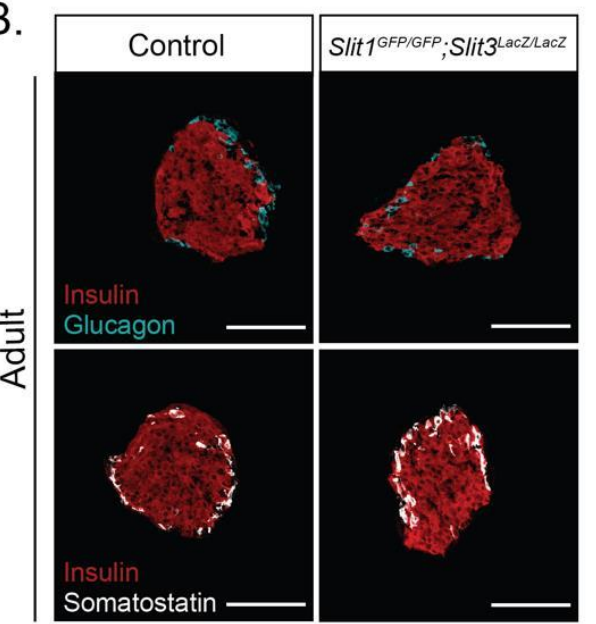

G.

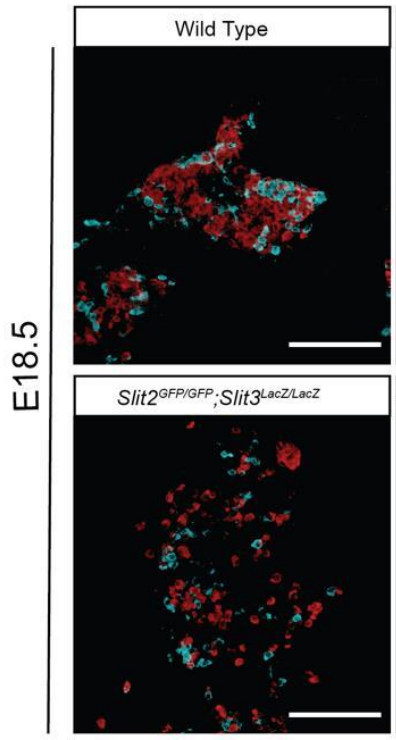

C.

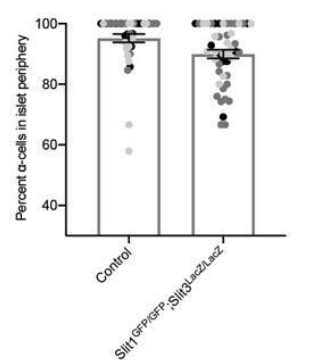

E.

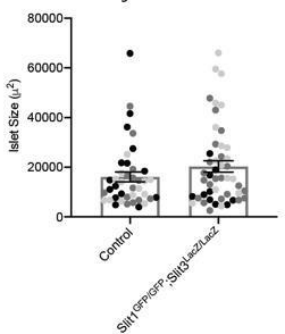

$\mathrm{H}$.
D.

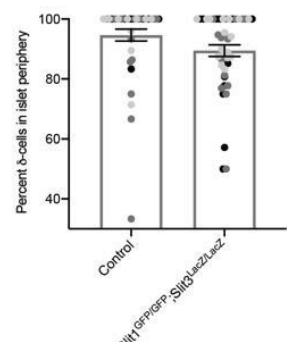

F.

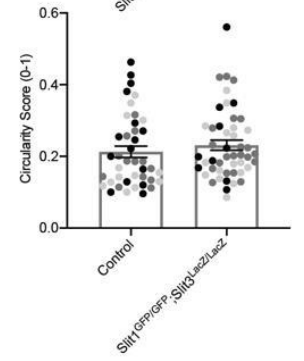

Figure 4: Slit2 and Slit3 compensate for one another in islet morphogenesis. (A) Amino acid alignment of the Robo-binding domain LRR2 (Slit1: 310aa-451aa, Slit2: 301aa-442aa, Slit3: 308aa-449aa) of all three murine Slits. In this region, the pairwise alignment scores are: Slit1/Slit2: 77\%, Slit1/Slit3: 69\%, Slit2/Slit3: 70\%. (B) Immunofluorescence staining of $\beta$-cells (Insulin, red), $\alpha$-cells (Glucagon, cyan) and $\delta$-cells (Somatostatin, white) in adult ( 8 week old) 


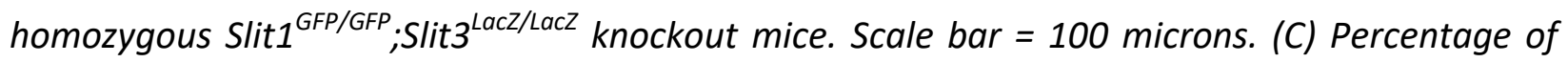
$\alpha$-cells found in the islet periphery out of total $\alpha$-cells. (D) Percentage of $\delta$-cells found in the islet periphery out of total $\delta$-cells. (E) Average islet size (F) Average islet circularity (as noted by a circularity score of $0-1$, where 1 is a perfect circle). Data presented as mean \pm SEM. (G) Immunofluorescence staining of $\beta$-cells (Insulin, red) and $\alpha$-cells (Glucagon, cyan) in control (wild-type), double, and triple knockout mice at E18.5/PO. Scale bar $=100$ microns. $(H)$ Percentage of islets from each genotype that were scored as intact, intermediate, or disrupted. Data presented as mean \pm SEM. $p<0.0001$; Chi-square test. 
A.

INS-1 Cells

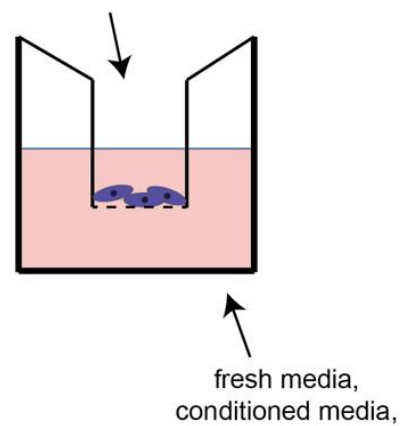

or conditioned media $+2.5 \mu \mathrm{g}$ recombinant SLIT

C.

Fresh Media

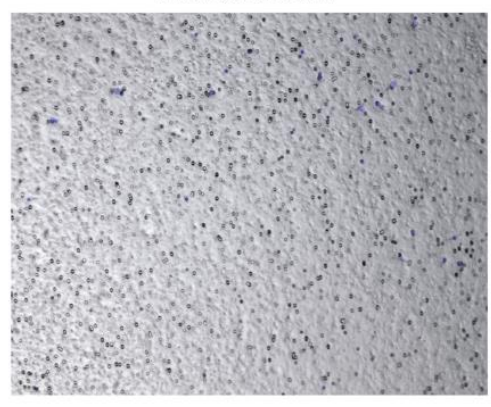

B.

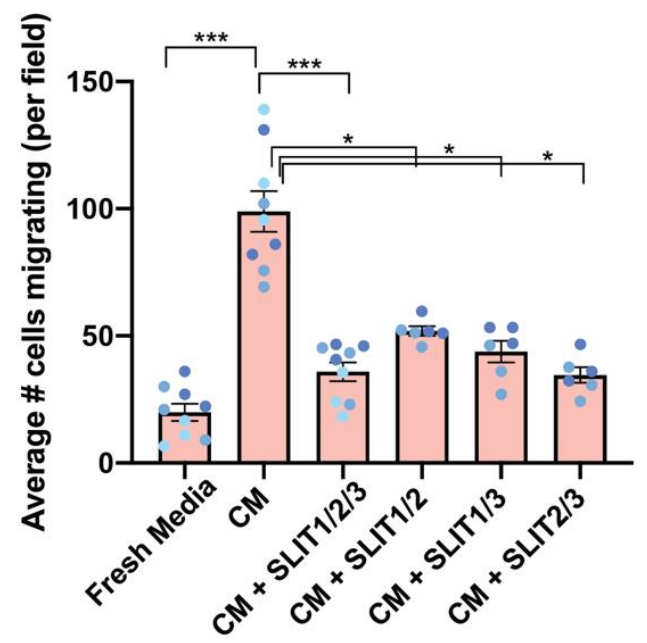

Conditioned Media + $2.5 \mu \mathrm{g}$ each SLIT
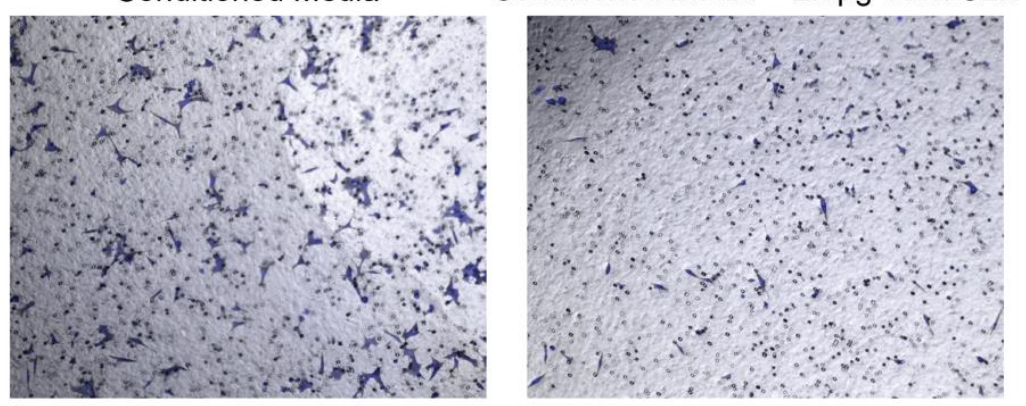

Figure 5: Slits act as repellent factors to influence $\beta$-cell migration. (A) Schematic diagram of Transwell cell migration assay. INS-1 cells were seeded in cell culture inserts over INS-1 conditioned media, fresh culture media, or INS-1 conditioned media supplemented with $2.5 \mu \mathrm{g}$ of each recombinant SLIT protein. (B) Results of cell migration assay. The average number of cells migrating per field of view is plotted. Data presented as mean \pm SEM. ${ }^{* * *} p<0.0005$ ${ }^{*} p<0.05$ (C) Representative images of a single field of view of a cell migration insert used in the experiments shown in (B). 

available under aCC-BY-NC-ND 4.0 International license.

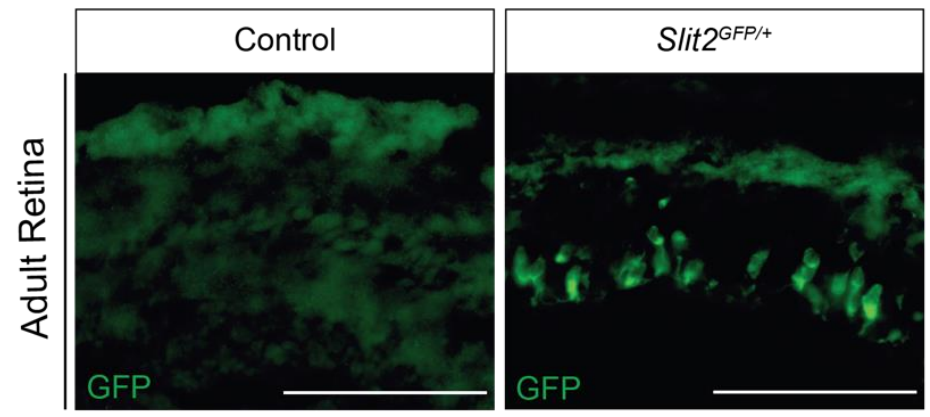

Supplemental Figure 1: The Slit2 ${ }^{G F P}$ reporter is functional. Immunofluorescence staining of Slit2 (GFP, green) in retinal sections from control (wild type) or Slit2 ${ }^{\text {GFP/+ }}$ heterozygous animals. Scale bar $=100$ microns. 